dispensary doing the usual out-door work of a hospital "; and $I$ am sure that most persons who are acquainted with hospital management will agree with you and with me upon this question.

My resignation of the honorary secretaxyship arose from the determination of the committee to recommend the increase of the medical staff from seven to nine, which I knew to be a course totally opposed to the practice of other hospitals, as well as to the rules of our own, and I did not wish to have the responsibility of carrying out a plan which I felt would be detrimental to the hospital.

I believe there are many reasons why a disproportionately large staff is not an advantage to a hospital; for instance, it very much increases the difficulties of nursing, and cannot materially conduce to the advancement of professional knowledge. I need hardly say that if a hospital is to succeed medically and surgically, which is the only true measure of success, each officer should have a sufficient number of beds to keep alive an interest in his work. Again, the severance of the in- and out-patient departments in so small a hospital would be an evil; it cannot be expected that two men would be willing to undertake the whole of the out-patient work without the smallest probability of having any beds at their disposal for many years to come, besides being obliged to hand over the most serious cases amongst the out-patients to the seven men who would retain the fifteen beds. My wish has been that the services of my colleagues should be retained. I regret that five of them decline to see the out-patients, and I was in hopes that my offer to continue seeing them two days a week, with the help of the sixth, leaving the other two days to the joint efforts of the five, would have solved the difficulty and obviated the wish for an increase of the staff.

Your remarks lead me to suppose that you cannot have seen my letter of resignation addressed to the governors, as you say-"We feel persuaded that Dr. Warwick will see, on reflection, that this letter betrays more solicitude for 'the establishment' than for the charity." From what I have now stated I think you will admit your conclusion to have been somewhat premature. The more I reflect on the matter the more I am convinced that four honorary medical officers, with a resident house-surgeon to act as secretary, would efficiently supply the whole service of the Richmond Infirmary until it becomes greatly enlarged; and that the endeavour to maintain what is defined in the rules as " the establishment" will be the most direct means of maintaining the best interests of the charity.

I beg to enclose you a copy of my letter resigning the honorary secretaryship.

I am, Sir, your obedient servant,

Richmond, S.T., February 24th, $1872 . \quad$ R. ARCHER WARWICK.

\section{SUBSTITUTE FOR THE OPHTHALMOSCOPIC MIRROR.}

To the Editor of THE LANCET.

SrR,-The ophthalmoscope having come into general use in medicine, it may save considerable embarrassment in choosing from among the vast variety of instruments offered to point out that we all possess one already in our watchpockets-riz., a watch-glass.

Any trapsparent reflecting body is an ophthalmoscope, and, with the ordinary lamp, quite enough light is returned from the concavity of a watch-glass to display all the details of the fund of the eye. It is used in the same manner as the mirror, but possesses this advantage, that (in viewing the inverted image) it may be held at any convenient distance from the observer's eye, so long as he looks through it. Therefore, if more light be desired, the watch-glass may be approximated to the patient's eye till all its reflection is concentrated on his pupil. Atropine is not required except in special eases, as there is no glare to provoke contraction of the pupil.

Any watch-glass will do provided the glass be (as it is in almost all of them) equally thick throughout, so as not to distort the image seen through it. Improved forms will, of course, at once occur to the reader-e.g., with a central convexity to enlarge the image or concavity to correct myopia; but to discuss these would be foreign to my purpose, which is merely to point out the use of what we have already got; the employment of which, I may add, wa suggested to me by the reports of some of Mr. Carter' admirable experiments.

I am, Sir, your obedient servant,

Heywood, Feb. 19th, 1872.

J. S. TORROP, M.D.

\section{THE NEW SANITARY BILL.}

To the Editor of THE LANCET.

SIR,-Will you allow me to suggest to the local secre taries to at once call a meeting of all union medical officers in each county town, so that the Sanitary Bill may receive consideration and support. The guardians in Worcester. shire are already contemplating a meeting, and there is nc doubt the Bill will receive active opposition in very manj quarters.-I am, Sir, your obedient servant,

WIr. WOODWARD, M.D.

Worcester, Feb. 24th, 1872.

Member of the Union Medical Officers' Association.

\section{BIRMINGHAM.}

(FROM OUR OWN CORRESPONDENT.)

THE small-pox epidemic is abating. The returns of reported cases show that during the week ending Feb. 10th there were 66 cases, while in that ending Jan. 13th there were 96 ; and, owing to the mildness of the season, the deaths from other causes have been so few as to reduce the death-rate to 21 . In Wolverhampton a very marked diminution of the small-pox is evident: only 6 deaths were recorded from that disease during the past week.

A memorial, signed by nearly all the leading physicians and surgeons, has been presented to the Corporation, asking for the appointment of a Medical Officer of Health. It is to be hoped that the Corporation will not oppose the prayer of so disinterested and public-spirited a body of men, but will be guided by the wise counsels of those who endeavour to prove to them that "salus populi, suprema lex."

A public park has recently been offered to the town by Miss Ryland, a generous lady, who has before on many occasions nobly supported the cause of the various charities, and to whom the "sanatorium" has up to the present time been indebted for "a local habitation." The estate, which is fifty-four acres in extent, and is situate within two miles of the centre of the borough, is valued at 230,000 , and its benevolent donor has further expressed her intention of spending $\$ 5000$ in laying it out as a public park.

A town's meeting has been held for the purpose of authorising the Town Council to apply to Parliament for an Act to make further provision for the improvement of the sanitary state of the borough. The scheme may briefly be said to do away with the open-midden system; to intercept fæcal matters so as to dispose of them without letting them enter the sewers; to discourage the use of waterclosets by rating each one annually at $10 \mathrm{~s}$; ; and to purify the sewage of the town by filtering it through land which the Council is to be empowered to acquire. The resolution in favour of the Bill was supported by Dr. Heslop in a powerful and argumentative speech, and carried with only three dissentients.

The recently erected out-patient department of the Children's Hospital has, owing to the deserved popularity of that institution, already proved too small for the largely increasing number of applicants, and a committee has been appointed to extend the present building in accordance with plans which have been approved by the medical committee.

The annual meeting of the governors of the Birmingham and Midland Counties Training Institution for Nurses has been held under the presidency of Lord Leigh. The report showed that the institution had been enabled to officer the Children's Hospital entirely, and the General and Queen's: Hospitals in part, and also to spare some few nurses for the Midland Asylum for Idiots; 110 private families had also been supplied with nurses. The total expenditure had been $£ 1282$, and the income, $\$ 905$. Large additional donations were announced, which will, we hope, relieve this useful institution from any financial embarrassment, and enable it to extend its sphere of usefulness. 